\title{
Projeto de um Sistema de Garantia de Qualidade para Empresa do Setor Têxtil
}

\author{
Edson Pacheco Paladini \\ Mestre em Engenharia de Sistemas \\ Doutorando em Engenharia de Produção \\ Professor Adjunto e Coordenador do Núcleo de Qualidade/Departamento de Eng. \\ de Produção e Sistemas da UFSC. \\ Campus Universitário - Trindade CP 476, 88049 - Florianópolis - SC.
}

Palavras-chave: controle de qualidade, sistema, estrutura, implantação.

Key words: quality control, system, structure, implantation.

\section{RESUMO}

A presenta-se, aqui, uma proposta básica de um projeto de sistema de Garantia de Qualidade desenvolvido e implantado em uma empresa têxtil dé médio porte, situada em Santa Catarina. A abordagem sistêmica, e, em particular, a metodologia de Checkland [1982] foi empregada para o desenvolvimento de uma estrutura organizada que deve responsabilizar-se pela garantia de qualidade de p'rodutos da empresa. Ao tempo em que relata uma aplicação prática de uma metodologia teórica, o presente trabalho procura apresentar alternativas viáveis para a fixaçāo de estratégias que visem a estruturar Sistemas de Garantia de Qualidade em empresas industriais.

\begin{abstract}
A basic project for a quality control for a medium-size textile industry is shown here. Both the development and implantation of the system are also discussed.

The systems approach, and the Checkland's methodology (1) in particular, is used to analyze the development of an organized structure which zuill be responsible for the quality assurance of the product and services offered by the industry.

In this article, we want not only to show a pratical application of a system theoretical methodology but also to present feasible options to select strategies for the quality system organization in industrial companies.
\end{abstract}

Rec. 01/91 Rev. 01/91 Apr. 02/91

PRODUÇĀO - Rio de Janeiro - Vol. 2 - №2 - março 1992 - p.p. 125, 132 


\section{Introdução}

Este artigo procura desenvolvera proposta de estrutura de um Sistema de Garantia de Qualidade em uma empresa industrial e das etapas pelas quais passa seu desenvolvimento. Utiliza-se, para tanto, a abordagem sistêmica e, em particular, a metodologia estruturada por Checkland [1982]. A implantação experimental da proposta ocorreu em uma empresa que fabrica produtos têxteis (malhas e confecções), situada em Santa Catarina, com cerca de 750 funcionários.

O uso da metodologia em questãojustifica-se pela necessidade de se buscar uma visão abrangente de todo o processo de produção e controle de qualidade, além de permitir que sejam estabelecidos passos lógicos nodesenvolvimentode todo trabalho de estruturação do sistema.

\section{Metodologia utilizada}

Por razões de espaço, a metodologia de Checkland não será descrita aqui. Sua estrutura poderá ser percebida no próprio texto do artigo. Informações adicionais podem ser obtidas nas referências listadas (1) e (2). O desenvolvimento do presente projeto adota as 5 fases propostas por Checkland [1982] e pode ser visto, esquematicamente, na Fig. 1.

Observa-se que, inicialmente, identificam-se os principais problemas do atual Controle de Qualidade (fase 1). A seguir, partindo-se de um Sistema Básico, são identificados dois supersistemas e quatro subsistemas (fase 2), todos com características próprias. Definido o sistema, monta-se o modelo conceitual, onde são identificadas as entradas, saídas e propriedades gerais do sistema (fase 3). Um modelo geral mostra como serão transformadas as entradas em saídas e descreve o moteiro de ação a ser desenvolvido pelo sistema. Uma estrutura interna para o Controle de Qualidade, dentro deste novosistema,é, entāo, apresentada. De forma suscinta, compara-se a situação atual com a situação desejada (fase 4). Antess de tomar alguma ação, define-se quais seriam as possíveis alternativas a empregar, sua viabilidade e, finalmente, uma análisse de possíveis reações às mudanças é feita (fase 5).

\section{Reconhecimento da situação problema}

É tarefa difícil, em geral, definir com clareza o que é e como deve funcionar um sistema de garantia de qualidade. Em geral, estas dificuldades são derivadas de um confinamento im posto ao controle de qualidade, a partir do qual sua ação fica restrita à área física do Departamento de Controle de Qualidade. Este equívoco compromete a ação de todo o Controle de Qualidade, definido, a priori, como um esforço amplo e abrangente, que envolve toda a fábrica. Estas dificuldades estão presentes na empresa sob estudo e podem ser, de uma forma mais objetiva, estruturadas em seis questōes básicas:

a) Falta de coordenação do esforço pela qualidade, quer a nível de setores, quer a. nível de pessoas;

b) Indefinição de responsabilidades pela qualidade (ou seja, funções específicas);

c) Relações confusas dosistema de qualidade com o meio ambiente;

d) Princípios gerais de funcionamento não fixados para o Controle de Qualidade;

e) Modelo administra tivo im preciso;

f) Confusão entre sistema de qualidade e departamento de controle de qualidade. 
Em termos de estrutura, hoje, a ação do controle de qualidade na empresa limita-se a três atividades básicas:

1 - Inspeção de produtos (não se aplica ao processo);

2 - Emissão de relatórios;

3 - Avaliação superficial de fornecedores.

São as seguintes as características da estrutura do setor de controle de qualidade da empresa hoje:

a) Estrutura física: o setor funciona em um conjunto de duas salas, sendo que $80 \%$ da área é tomada pelo laboratório de fibras e tecidos. As salas são "internas" à fábrica, situando-se próximas às linhas de produção.

b) Estrutura hierárquica: a administração do setor é exercida por um supervisor, que se reporta ao Gerente Industrial. $O$ supervisor tem dois subordinados - o chefe de laboratório e o chefe de inspeção - cada um com um conjunto de técnicose inspetores, respectivamente, ligados a eles. O apoio é exercido por duas secretárias e um office-boy.

c) Relatórios formais: são trêsos documentos básicos emitidos pelo setor: (1) Relatório de exame (R.E.), que contém os resultados dos testes feitos em laboratório; (2) Relatório de inspeção (R.I.), que envolve os resultados das inspeções feitas em linha; (3) Avaliação de fornecedores (A.F.), que relata os níveis de qualidade observados nos produtos adquiridos.

d) Eficácia das informações fornecidas: Os R.E.'s são divulgados com atraso, por causa da demora dos testes. Há muita reclamação por causa disto. OsR.I.'s são imediatos, mas vêm com uma linguagem muito confusa. A A.F. é um documento do qual não se ouvem reclamações.
Indiscutivelmente, porém, é uma avaliação muito parcial (e fraca) de fornecedores.

Quanto ao processo produtivo, tem-se:

a) Planejamento: praticamente inexiste. Uma vez definido o plano de produção, definem-se as inspeções e testes que serão necessários. As A.F. são em tidias exclusivamente sob solicitação.

b) Execução: rotinas prontas indicam como executar os testes, inspeções e avaliaçōes.

c) Registro de dados: os relatórios, rotinas e outros documentos relativos aos resultados dos testes são emitidos em 2 vias, uma destinando-se ao setor envolvido e outra sendo arquivada no próprio departamento. Há ainda registros de patrimônio, estoque de produtos para testes, pessoal e métodos de trabalho. Estesficam noarquivo $B$; os primeiros, no arquivo $A$.

d) Ações de controle: as inspeções e testes são checados pelo processo da contraprova. Auditorias periódicas sãotambém empregadas para avaliar o desempenho de inspetores.

Há, ainda, outros aspectos a destacar:

a) A ação do controle de qualidade fica restrita às suas atividades básicas, sem qualquer ação sobre a produção;

b) Não há uma relação direta entre o setor de Controle de Qualidade e os setores produtivos da fábrica;

c) Apesar de existirem rotinas de trabalho, considera-se que o funcionamento do departamentodependedomomento, sem se identificar um princípio geral de ação.

d) OControle de Qualidade limita-se a açōes muito particulares. 
Observa-se, em geral, queestes problemas podem facilmente ser reduzidos às seis questões anteriormente listadas.

\section{Definição do sistema, subsistemas e supersistemas}

Os seguintes elementos básicos relativos ao problema em estudo podem ser identificados:

a) Sistema: Sistema de Garantia de Qualidade da Empresa.

a.1.Domínio: a empresa ea administração industrial.

Ao primeiro caso, agrega-se a administração da empresa (conselho) e, ao segundo, as pessoas do diretor $\mathrm{e}$ do gerente industrial.

a.2. Atores: técnicos, pessoal de a poio e administração do setor.

a.3. Transformação: elaboração de diagnóstico (reconhecimento de situações). Hojeo processo de transformação se resume a isto.

a.4. Clientes: setores produtivos; gerência industrial; compras; diretoria comercial.

b) Supersistemas: Empresa e Área Industrial

Toda a ação da sistema deve ser guiada pelas decisōes e políticas da empresa, em geral, e, em particular, da administração industrial. Os elementos seguintes podem ser considerados como restriçōes impostas, ao sistema, pelos supersistemas:

- Ações esperadas (ou delegadas) pela administração da empresa ou da diretoria (gerência) industrial;

- Recursos materiais e financeiros para funcionamento do sistema;

- Fluxo de informações entre o supersistema (empresa) e o setor, bem como entre a administração industrial e o setor;

- Recursos Humanos alocados no setor;

- Espaço físico;

c. Subsistemas: Técnico, Administrativo e Apoio, ou seja:

- Administrativo: supervisor echefe (laboratório e inspeção).

- Técnico: pessoal, equipamentos, informações, métodos, materiais e ambiente de realizações dos testes. Idem para a inspeção, excluindo-se, éclaro, oambiente, que é a própria fábrica.

- Apoio: secretaria, office-boy, manutenção e rede de comunicação.

Há, ainda, um subsistema adaptativo responsável pela previsão das atividades a desenvolver.

\section{Concepção do modelo}

Deforma esquemática pode-se descrever os elementos do modelo proposto como segue:

a) Definição do Sistema de Qualidade:

"Sistema dinâmico que envolve, direta ou indiretamente, todos os setores da empre- 
sa, com o intuito de melhorar e assegurar economicamente, a qualidade de produtose serviços da empresa". (Paladini, 1990).

b) Desenvolvimento do Modelo Conceitual:

\section{b.1. Saídas:}

- Criar uma estrutura abrangente, que coordene o esforço pela qualidade, identificando, com clareza, responsabilidadespela qualidade, bem como açōes integradas a serem desenvolvidas por todos os setores produtivos.

- Direcionar a açāo do controle de qualidade para fins preventivos, ao invés de, simplesmente, trabalhar com diagnósticos.

- Racionalizar o fluxo de informaçfōes que afetam a qualidade.

\section{b.2. Entradas:}

- Política da empresa em termos dequalidade;

- Procedimentos básicos de inspeção e análise;

- Produtos e serviços a serem avaliados.

\section{b.3. Outras propriedades básicas:}

- Objetivos: promover adequada avaliação do nível de qualidade dos produtos $e$ serviços da Empresa e, ao mesmo tempo, desenvolver uma mentalidade voltada para a prevenção dos defeitos detectados (as saídas operacionalizarão estes objetivos).

- Medidas de desempenho: a avaliação de parâmetros básicos como nível de qualidade aceitável, a fração defeituosa tolerável e os riscos (do produtor e do consu- midor) representará a medida do nível de qualidade do produto em termos das respostas oferecidas aos estímulos do sistema de qualidade. Por sua vez, os resultados das auditorias periódicas que serão feitas nas linhas de produção e no laboratório, mostrarão o grau de desempenho do sistema em termos de avaliação da qualidade.

- Ambiente: os setores produtivos da fábrica e os fornecedores.

- Recursos: pessoal, equipamentos, informações, canais de comunicação, métodos e rotinas de trabalho e materiais. Recursos financeirose deespaço físico para operaçāo do sistema são também relevantes.

- Processo decisório: definição de aceitação (e, portanto, liberação) e rejeição (e, portanto, retenção) dos materiais inspecionados deve equivaler a uma decisão a ser adotada pela fábrica. Outras decisões de natureza operacional ficarão restritas ao sistema em si (por exemplo, métodos de inspeção a adotar).

- Fronteiras: embora limitado às atividades técnicas específicas e centrado em ações que visam a induziro controle preventivo, o sistema deve alcançar toda a fábrica e envolver, também, açōes do Setor de Compras', que guiar-se-á pelas A.F.'s na seleção de fornecedores.

A transformação das entradas em saídas será possibilitada por um conjunto de atividadesespecíficas (Fig. 2). Esteéo modelo conceitual do sistema. Sua ação dar-se-á por um processo reflexivo (ver figura 3). Finalmente, sua estrutura interna será específica (ver figura 4).

Comose percebedo modelo, as atividades básicas para atingir as saídas são: 
O Quadro abaixo compara o modelo conceitual e a situação-problema:

\begin{tabular}{|c|c|c|}
\hline \multicolumn{2}{|r|}{ SITUAÇÃO EXISTENTE } & SITUAÇÃO PROPOSTA \\
\hline 1 & $\begin{array}{l}\text { Ação restrita do Controle de } \\
\text { Qualidade. }\end{array}$ & $\begin{array}{l}\text { Ação abrangente, envolvendo } \\
\text { toda a fábrica }\end{array}$ \\
\hline 2 & Enfoque corretivo: & Enfoque preventivo. \\
\hline 3 & $\begin{array}{l}\text { Ações isoladas em prol da } \\
\text { Qualidade. }\end{array}$ & $\begin{array}{l}\text { Ações integradas, coordenadas } \\
\text { e motivadas pela administração } \\
\text { do sistema. }\end{array}$ \\
\hline 4 & $\begin{array}{l}\text { Responsabilidades } \\
\text { identificadas. }\end{array}$ & $\begin{array}{l}\text { Definição clara de funções / } \\
\text { responsabilidades. }\end{array}$ \\
\hline 5 & $\begin{array}{l}\text { Fluxo imperfeito de } \\
\text { informações. }\end{array}$ & $\begin{array}{l}\text { Fornecimento de informações } \\
\text { corretas, adequadas e em } \\
\text { tempo hábil, via canais } \\
\text { eficientes. }\end{array}$ \\
\hline 6 & $\begin{array}{l}\text { Confusão entre setor e sistema } \\
\text { de Qualidade. }\end{array}$ & $\begin{array}{l}\text { Setor de Qualidade: órgão de } \\
\text { apoio à ação do Sistema de } \\
\text { Qualidade. }\end{array}$ \\
\hline
\end{tabular}

1. Organização do sistema;

2. Definição das funções a exercer;

3. Administração do sistema;

4. Motivação à qualidade;

5. Planejamento de atividades.

\section{Definição de possíveis mudanças}

Para sua implantação, foram requeridas alteraçōes significativas nas atividades da fábrica, sendo as mais relevantes as que dizem respeito à ação do Controle de Qualidade sobre a fábrica (produtos com prados/ 
fabricados dependem de liberação do Controle de Qualidade), alteraçãoda mentalidade de controle (motivar para a prevenção), abrangência da ação do Controle de Qualidade (setores produtivos são co-responsáveis pela qualidade), integração de esforços (atividades integradas produção/qualidade), estruturação de sistema específico de informações para a qualidade, definição da natureza técnica das atividades do setor de qualidade, diagnóstico (mais rá pidos e precisos, estrutura hierárquica (controle de qualidade com status de Gerência) e avaliação de fornecedores.

Um cronograma detalhado determinou as ações já implantadas e aquelas que em período específico deverão ser viabilizadas para que possam ser efetivadas todas as mudanças previstas no Planode Implantação do Sistema. Estima-se em 2 anos o tempo requerido para a execução de todo o Plano.

Algumas das mudanças propostas, ainda que plenamente viáveis do ponto de vista prático, trarão modificações consideráveis nas atividades rotineiras da fábrica. Entre essas destacam-se:

a) Dependência de liberação de produtos comprados ou produzidos por um dado setor, pelo Controle de Qualidade. A ação ativa dos inspetores tanto poderá incomodar gerentes e chefes de setores como trará reflexos em termos de estoques $\mathrm{e}$ planejamento e controle da produção.

b) Novo status do encarregado do Controle de Qualidade, que passa para o nível igual ao do Gerente Industrial;

c) Modificação nos procedimentos comerciais relativos à compra de matériasprimas. Agora, além de preço e prazo, niveis de qualidade serão relevantes; isto requer novas posturas do pessoal de compras; d) A médio prazo, haverá a cobrança dos gerentes, por parte da alta administração, por resultados em termos de qualidade. São novas ações e tarefas que eles terão de desenvolver.

Ainda que as mudanças listadas signifiquem ações de conscientização e chamadas à participaçãodo pessoal no processo, parece inevitável o aparecimento de resistências às mudanças que serăo introduzidas.

Uma análise de problemas em potencial deverá ser, então, desenvolvida. Pela experiência em casos semelhantes, entretanto, pode-se definir, preliminarmente, uma linha de estratégias a seguir:

- pretende-se mostrar que o novo sistema procurará tornaros recursos humanos da fábrica em agentes ativos do processo de melhoria da qualidade; não existe a idéia de descartá-los, mas sim envolvê-los sempre mais. Assim, primeiro deseja-se sua participação no sistema; a seguir, sua adesão a ele.

Além disso, a implantação do processo será feita considerando-se 4 aspectos básicos prioritários:

1 - A alta administração da Empresa não apenas apóia, mas participa ativamente da implantação do novo Sistema. Este fato terá ampla divulgação.

2 - Os benefícios do novo sistema são inegáveis e deverão ser convenientemente demonstrados. Pretende-se, assim, convencer as pessoas de sua utilidade, conveniência e, acima de tudo, adequação à realidade da empresa.

3 - Mudanças a serem introduzidas serão feitas de forma lenta e gradativa; nem tão rápido que pareça impacto, nem tão lento que não cheguem a ser percebidas. 
Assim, a mão-de-obra será envolvida por elas.

4 - Procurar-se-á evidenciar que o sistema merece crédito; as pessoas podem (e devem) colocar suas fichas nele.

Assim, procurar-se-á obter aliados na fábrica; não se deseja, de forma alguma, inimigos-declarados ou não-que, em futuro próximo acabem por sabotar o sistema.

Finalmente, cabeobservarque, ainda que se busque participação e apoio às novas atividades; ainda que elas sejam lentamente introduzidas; ainda que se deseje envolvera todos, com consciência, no processo, as mudanças serão implantadas por decisão da administração da em presa. Desta forma, em uma etapa posterior, cabe esperar que, no interesse da organização, as pessoas se adiaptem a elas. Fora disto, não restarão muitas opções.

\section{Conclusões}

Resultados preliminares mostram a plena viabilidade do sistema proposto e ressaltam a necessidade e conveniência de sua implantação. Em particular, a participação de toda mão-de-obra no esforço pela qualidade, a integração da Alta Administração da empresa no esforço pela qualidade e os benefícios práticos advindos da implantação das mudanças propostas sãoelementos vitais a serem conquistados.

Fica, assim, evidenciada a adequação da metodologia proposta ao problema especifico em questão, identificando-se para ela, nova aplicação e, para o probleina de estruturação de sistemas de qualidade, uma nova abordagem, cujos resultados iniciais indicam sua utilidade e relevância.

\section{Bibliografia}

1. CHECKLAND, P.B. Towards a SystemsBased Methodology for Realwold problem Solving. Systems Eng., v.3,n. $2,1972$.

2. CHECKLAND, P.B.Systems Approach to Management. Systems Eng., v. 3, n.1, 1972.

3. PALADINE, E.P. Controle de Qualidade: Uma Abordagem Abrangente. São Paulo, Editora Atlas, 1990. 